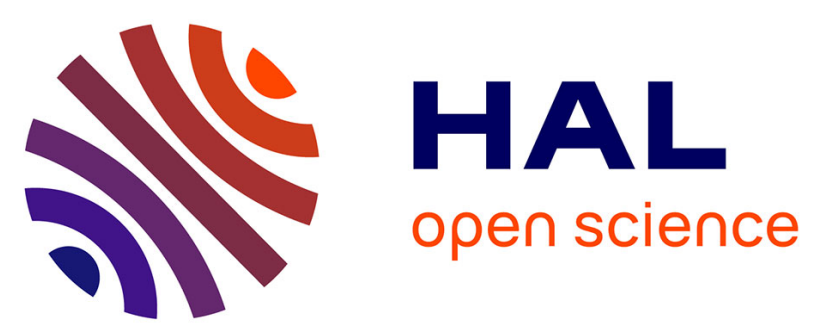

\title{
Towards a Pattern-based adaptive approach for Instructional Design Based on Teacher's Pedagogical Design Scheme
}

\author{
Jean-Pierre Clayer, Claudine Piau-Toffolon, Christophe Choquet
}

\section{- To cite this version:}

Jean-Pierre Clayer, Claudine Piau-Toffolon, Christophe Choquet. Towards a Pattern-based adaptive approach for Instructional Design Based on Teacher's Pedagogical Design Scheme. 15th Int. Conf. on Enterprise Information Systems (ICEIS'13), Jul 2013, Angers, France. pp.532-538. hal-01452340

\author{
HAL Id: hal-01452340 \\ https://hal.science/hal-01452340
}

Submitted on 24 Aug 2018

HAL is a multi-disciplinary open access archive for the deposit and dissemination of scientific research documents, whether they are published or not. The documents may come from teaching and research institutions in France or abroad, or from public or private research centers.
L'archive ouverte pluridisciplinaire HAL, est destinée au dépôt et à la diffusion de documents scientifiques de niveau recherche, publiés ou non, émanant des établissements d'enseignement et de recherche français ou étrangers, des laboratoires publics ou privés. 


\title{
Towards a Pattern-based adaptive approach for Instructional Design Based on Teacher's Pedagogical Design Scheme
}

\author{
Jean-Pierre CLAYER, Claudine TOFFOLON, Christophe CHOQUET \\ LIUM Laboratory, PRESUNAM, Le Mans, France \\ Avenue Laënnec 72085 Le Mans Cedex 9 \\ \{jean-pierre.clayer, claudine.piau-toffolon, christophe.choquet\}@lium.univ-lemans.fr
}

Keywords : $\quad$ Instructional Design, Pattern, Pedagogical Design Scheme, Design Based Research approach

\begin{abstract}
Learning is changing in deep, activities of teaching practitioners have to evolve. They need to structure and formalize their internal designs as models to be implemented but do not have competences in instructional design. We propose to use patterns, semi-structured description of an expert's method for solving a recurrent problem to elicit and express theirs needs. We propose an engineering design process framework based on patterns, and pedagogical design schemes to support instructional design. A tool has been developed to support this process. We experiment a design session with two trainers of an association dedicated to back-to-work programs within an iterative co-participant design based research method.
\end{abstract}

\section{INTRODUCTION}

Learning and teaching is changing due, on one hand to the evolutions of the society expectations and, on another hand to the widely spreading of new technologies. Teaching, an unstructured, informal world of much professional practice need design principles. Designing learning is a complex task [Rohse \& Anderson 2006]. Teaching practitioners need to structure and formalize their scenarios (lessons plans) as models to be implemented but do not have specific designer competence to easily achieve it. To design, they require a mean to elicit and express their needs_[Bonnardel 2009].

The research field has produced a set of design process, methods and tools offering effective mechanisms and notations to design different issues in pedagogical or instructional topics. We get attention in particular to those approaches which deal the instrumentation of instructional design, specifically learning scenarios centered. The wellknown modeling approach by the help of Educational Modeling Languages (EML), as the IMS Learning Design specification [Koper \& Olivier 2004] leads to enable the design of computational models (in the meaning of understandable by a computer) which could be enacted by compliant systems. However these specifications are not really usable by teachers, need pedagogical engineering expertise and do not enforce design processes that support the creation of pedagogically sound designs [Hernandez-Leo et al. 2010]. Some limitations and shortcomings have been identified to deal with the teaching practitioners new tasks of learning design. Teachers found difficult to express their needs or to reuse their design products. Most of the time, not enough assistance and guidance are provided. A second approach is to allow designers (may be assisted by modeling specialists) to define their own EML by specifying a domain-specific and to use it for building their scenarios [El-Kechaï \& Choquet 2006]. Our research work is based on this second approach and states that teachers are able to build their learning scenarios by the uses of patterns.

We adopt a practitioner-centered point of view to deal with the learning design activity based on patterns approaches [Hernández-Leo \& al 2006][De Moura 2008][Emin \& al 2010]. Patterns are semistructured description of an expert's method for solving a recurrent problem which includes a description of the problem itself and the context in which the method is applicable [Mor \& Winter, 2007]. Patterns are "good solutions" to deal with complexity characterizing the education field [Rohse \& Anderson 2006]. According to Laurillard's works [Laurillard 2012], this approach is immediately relevant to teachers as it presents means by which a community can participate in design. This formalism offer the opportunity to the teacher to externalize his knowledge [Goodyear, 2005] and to express his practice which can become a best-practice.

We propose an engineering design approach based on pattern notation to benefit its potential to 
facilitate the expression of pedagogical concerns for teaching practitioners. We defined an engineering iterative design process framework and an associated tool to support the design activity of practicing teachers. This tool may support the design activity of scenario of teacher by proposing adaptations, according to the design context and pedagogical design scheme. We experiment a design session with the trainers of an association dedicated to back-to work programs within a design research based approach.

In the next section we present the research context. The concepts of patterns and pedagogical design schemes are explained in the third section. Then we propose our engineering design process framework. Next we present the three main steps of the experiment with trainers of the association. Then we discuss the resulting set of design research guidelines produced for researchers and teachers.

\section{THE RESEARCH CONTEXT}

Patterns have been used in the 70's in the field of building architecture, by Christopher Alexander [Alexander \& al, 1977]. Several repositories of patterns exist for various disciplines and offer design expertise reuse to the corresponding communities as the object oriented programming community or the HCI community. A pattern is defined by three main properties: a problem, a context of this problem and a solution [Alexander \& al, 1977] [E-LEN, 2012]. Each pattern captures the best practice to answer to a problem in a particular context. The formalism of patterns differs depending on the type of problem that the pattern solves. Each formalism adds specific information for the category of problem to solve. By their formalism, patterns support the creativity without constraints. Users are guided rather than forced in the use of patterns [Rohse \& Anderson, 2006]. This approach is particularly interesting with novice teachers. A pattern language describes the relations between patterns (associate, compose of...) that captures the whole design process and can guide the designer through step-by-step design guidelines [Alexander \& al, 1977].

In particular in the e-learning community many projects as Pedagogical Patterns Project [PPP, 2011] or Design Patterns for recording and analyzing Usage of Learning Systems [DPULS, 2005] proposed a catalog of patterns concerning learning strategies types of problem. In this way designers of new or existing LMS, especially inexperienced designers, through the use of catalog of patterns can take advantage of previous design expertise [PPC, 2012] [E-LEN, 2012] [Delozanne \& al, 2007].

Researchers in education get increasing interest with pattern-based design approach. COLLAGE, a collaborative learning flow pattern (CLFP) editor [Hernandez-leo, 2006] proposes a pattern based visual design approach implemented in RELOAD. This approach is based on the IMS-LD specification which enables the modelling of learning processes. The MDEduc project proposes a Pedagogical Patterns Editor for the design of learning scenario using the formalism and syntax of patterns [De Moura, 2008]. ScenEdit and the model ISIS support also a pattern based approach to design learning scenarios [Emin \& al 2008]. These approaches help teachers to better express their pedagogical needs but they still lack process and tool support for the design activity of learning scenarios. They are also based on existing design plan. We deal with these limitations in the next part of the paper.

According to the design problems highlighted previously in teaching domain, we explored the TEL engineering domain best practices and the software engineering patterns solutions implemented in the information system domain. A pedagogical situation is composed of different elements defining a scenario: Learning strategies, Learning situations, Objectives, Activities, Human resources, Material resources. We take into account of these elements within four categories of pedagogical problem: Activity design, Learning situations design, Ressources design and Pedagogy. We identify four formalisms of patterns to solve the four types of problem.

Pedagogical patterns are describing learning strategies and objectives. These types of patterns seem to us well suited to present the information on the pedagogical method in use [Bergin, 2000].

Analysis Patterns are well-suited to describe material and human resources because of their structure which allows defining the use of a material or a role [Fowler, 1997].

Process Patterns are well-suited to describe pedagogical activities and tasks realized as a workflow of the actions or sub-tasks [Amber, 1998]. 
Design Patterns are well-suited to describe learning situations. as they are used to resolve a problem of learning design [Gamma et al, 1995].

Teaching design depends on learning theories. For a learning theory, many approaches may be defined. Project-based learning is a kind of pedagogical approach related to the active learning theory. A typology [Villiot-Leclercq, 2007] distinguishes the different approach for each learning theory. A set of methods and tools are defined for a specific pedagogical approach and underpinned the creation of the scenario and its pedagogical elements. The choice of the pedagogical approaches and the learning strategies allows identifying the type of learning scenarios [Paquette, 2004].

The design process of a scenario according to a specific pedagogical approach defines what we named pedagogical design schemes (PDS). A pedagogical design scheme is the approach for designing a course, in our context, a learning scenario.

Early instructional design approach developed concepts for systematically designing instructional materials. The IMSL-LD specifications are based on a learner activity driven approach [Koper \& Oliver 2004]. This type of languages provides best practices guides driven by the efficiency of the modeling rather than pedagogical design schemes. Editors/tools developed for these languages instrument usually the modeling activity guided by a given design approach, underlying implicitly the interfaces design.

Most of pattern-based design approaches are driven by PDS. In [Emin, 2010], the design process supported by the ISIS model is driven by a strategies and intentions pedagogical design scheme, that mean the design of scenario is driven by intentions and strategies. The COLLAGE approach with the collaborative learning flow patterns is driven by the learning activities PDS [Hernandez-Leo 2006].

The design of pedagogical scenario is constrained in these approaches by a specific PDS.

When teaching practitioners design a learning scenario with the same objective and learning situation, their pedagogical design schemes may not always be the same. For the same design problem, many pedagogical design schemes may exist.

\section{Patterns, Pedagogical Design Schemes AND DESIGN PROCESS}

\section{A. Patterns}

According to the DSM approach, a meta-model [Clayer et al. 2012] has been defined to describe the language of patterns. This language use four formalisms of patterns: Pedagogical Patterns, Analysis Patterns, Process Patterns and Design Patterns. According to this language, we represent the pedagogical elements of a scenario with these formalisms.

The figure 1 illustrates the simplified graphical form of a pattern. This form presents only the most important element of a pattern: a name, a problem, a context and a solution.

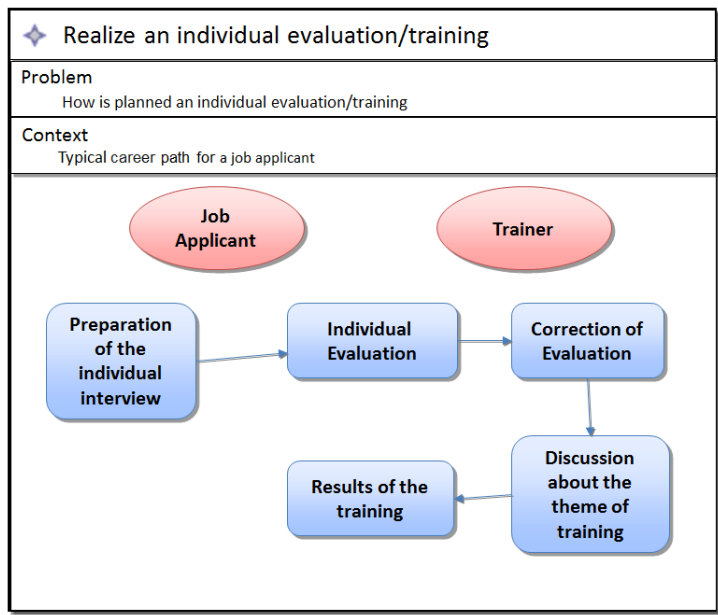

Figure 1: Simplified Graphical Form of Process Pattern

We represents the activity "Realize an individual evaluation/training" by a process-pattern according to the meta-model [Clayer et al. 2012]. The problem and context are in a textual form. The solution is composed with a list of activities and the role of participant.

\section{B. Pedagogical Design Schemes (PDS)}

To assist the designers, we identify their learning design activity based on their PDS. PDS is defined by an oriented graph of the pedagogical elements. The beginning of the oriented graph and the first pedagogical element give the orientation of the PDS. For example, figure 2 illustrates a pedagogical design scheme collected during the experiment. This 
pedagogical design scheme is driven by the objective.

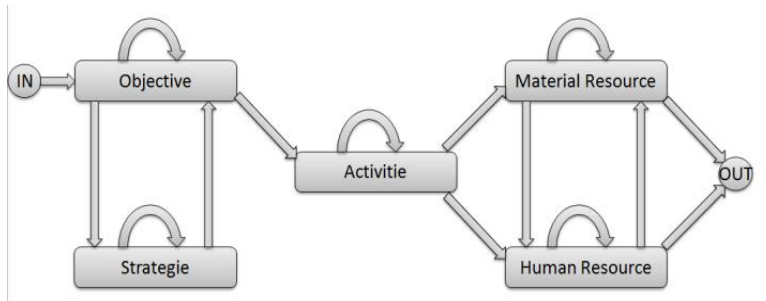

Figure 2: Objectives Driven PDS

The oriented graph contains only one occurrence of each pedagogical element. Designers can't design each type of pedagogical elements when they are applying a given PDS. The link between the pedagogical elements give us the next possible design activity for the current design activity. The design activity is identified to know the next and the previous design activity in order to anticipate the next action of the designer and propose assistance (the selection of the next pedagogical element according to the pedagogical design scheme identified) or guidance (invite the designer to check its current design).

\section{Design Process}

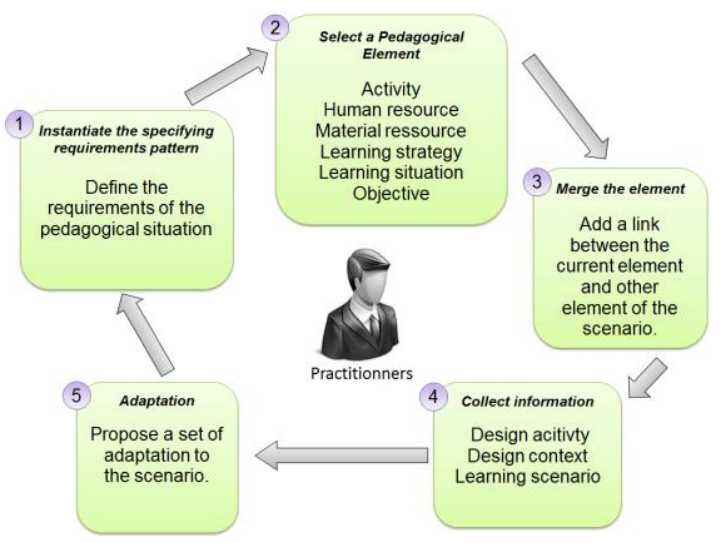

Figure 3: Engineering design framework

We propose an engineering design framework to support the design process based on patterns. The design process is compliant with any kind of pedagogical design scheme and support the identification of the current activity and design context to offer guidance to the designer based on adaptive rules. The design process is iterative and consists of the following steps (Figure 3):

1. Instantiate the specifying requirements pattern: as designer, the teacher/trainer has to define the requirements of the pedagogical situation (objectives, resources, tools, learning strategy, actors, roles, etc.);

2. Select a pedagogical element: the designer can choose an existing pattern or creates a new one. Designer does not manipulate patterns but the pedagogical element represented by the patterns. The pattern complexity is hidden to the designer. According to the learning context, the designer defines parameters to select the most relevant pedagogical element. He can choose one element among the pedagogical elements proposed by the editor: learning situations, human or material resources, activities, pedagogical strategies or objectives.

3. Merge the element: The designer has to associate the selected element to the ones he has already selected during previous iterations. The scenario is updated with the selected element and both user's actions and element properties are collected to be analyzed.

4. Collect information: The information collected are analyzed. According to this analysis, the design context is updated and the adaptation rules could be fired.

5. Adapt the solution: A set of possible adaptations is proposed to the designer, according to the fired rules set. Adaptations could lead to provide some recommendations on the design method, or to propose pedagogical element related to the user's action, better suited for the design context.

\section{Editing Tool for Pedagogical Scenario}

We develop an editing tool to support the design process. The editor is generated into the EMF-GMF framework [Kelly, 2007], from the meta-model of Patterns [Clayer et al., 2012]. The adaptation part of the process has not been implemented yet in the editing tool. It will consist in an adapting system based on the design context and able to adapt the domain specific-models and the editing interface according to the DSM features. The interface of the tool allows the designer to visualize the patterns (pedagogical elements) he instantiates as frames divided in four boxes: one for the pattern name, one for the context, one for the statement of the problem 
and one for the graphical representation of the solution (Figure 4-A). A toolbox (Figure 4-B) provides the design primitives (pedagogical elements: objective, pedagogical strategy, material resource, human resource, activity, learning situation). Finally, information concerning the pattern is also accessible through the tab property (Figure 4-C).

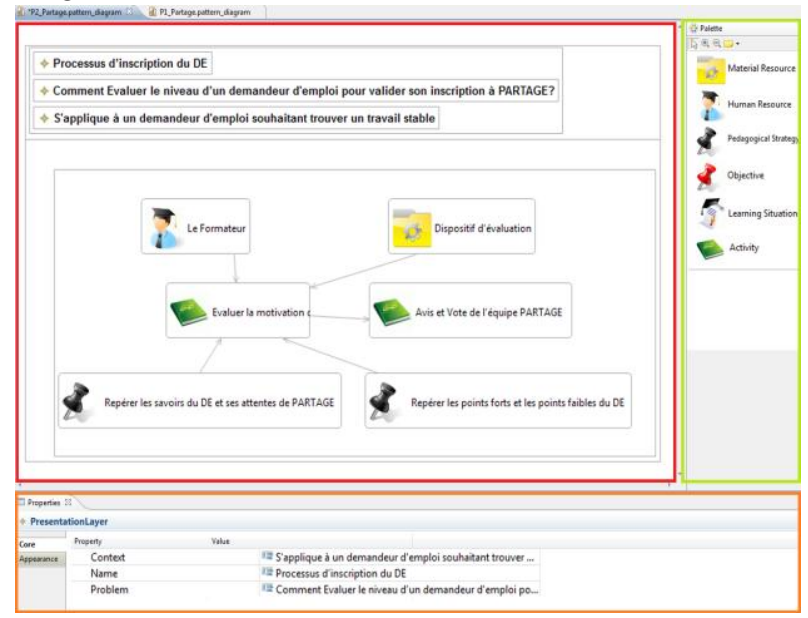

Figure 4: Editing tool

\section{EXPERIMENT}

We have realized an experiment with the professional trainers of a registered association PARTAGE dealing with professional integration, in charge with back-to-work programs. PARTAGE provides trainings essentially based on formative evaluations supported by classical pedagogical resources and methods (teacher-learner based strategy). Supports for trainings are not always welladapted to the public. The public is composed of adults sometimes not always comfortable with trainings and classical paper-based support. The association also faces many changes within its trainers staff.

PARTAGE has expressed to us their needs based on two aspects. Firstly, they would like to produce computerized pedagogical materials in order to facilitate reuse and adaptation. Secondly, they were interested by a tool to support their design sessions in order to produce scenarios better adapted to their heterogeneous public. They would like to capitalize the training practices of the constantly evolving trainers staff and get assistance when designing the training scenarios, and share those practices between them.

We worked with two trainers within an iterative participatory design based research approach. Trainers took part in the activities of analysis and design many times in a collaborative work with the research team. Trainers arrived with scenario paper based written scenario and follow the design process proposed in previous section in an iterative way.

\section{A. Design of PARTAGE Patterns}

During this first session, we have observed the practices of the association during working meetings and trainings. The association has defined a process for their professional integration programs. The main outcome of this process is to provide employment to their members depending on their individual profile and skills.

One of the steps of this process is composed of training, most of the time based on evaluation. During this training evaluation step, the skills of learners are evaluated, according to a category of work, by a trainer with the support of different pedagogical resource/material.

The trainer prepares the evaluation training according to the learner abilities and the available resources. The trainer designs a learning scenario on paper to describe the learning situation and the pedagogical elements associated.

We have collected information on the association practices by the observation and interviews of trainers in a need's analysis report. On the basis of this report, we have designed some patterns (Figure $1)$.

A set of patterns which describes the learning situations, the pedagogical elements and some scenarios we observed has been proposed to the trainer in charge with the association.

We have proposed other set of patterns to the association leader. She approved this representation of their practices within patterns. She reports that "the design approach based on patterns forced the trainers to have more rigor and help them to express their needs". Nevertheless, she noticed some difficulties to understand some part of the patterns formalism. Some terms used to define a section of patterns were not familiar to the trainers. They recommended us to support the design of pattern with a textual description. 
During this first step of the experiment, we have collected a lot of practices and captured them in patterns.

\section{B. Prototyping tool demonstration}

We have developed a first version of the editor prototype to support our engineering design framework. To reify the design approach, we planned a working meeting to present the prototype, and resulting patterns and scenarios designed in the first step of the experiment. We asked them to evaluate the resulting scenarios and the tool implementing them, an attention was given to the pedagogical design scheme.

We have demonstrated the design of a scenario with the tool to the trainer. After the demonstration, we asked for an evaluation of the tool. The trainer noticed the lack of user friendliness of this first version prototype. Despite these limits the trainer has appreciated the opportunities of formalization of the pedagogical scenario and the expressiveness of the artifacts resulting from the editing session.

\section{Collecting PARTAGE Pedagogical design schemes}

We have improved the prototype to take into account observations made by the trainer during the previous session. Use of patterns is not explicit for designers, they handle elements of scenario of the learning situation : define activity, actors, resources, and so on.

In a third session we proposed to the trainer to implement a scenario of a new session of their training programs using the editing tool. This time two trainers were implicated. They aimed to implement the same learning situation but we noticed that they had two different way of formalizing it. We identified different pedagogical design schemes for the same learning situation.

They designed a complete scenario of the learning situation but following different types of pedagogical design schemes (PDS).

We noted that trainers were able to handle the prototype of the editing tool in only thirty minutes despite a lack of user friendliness of the tool.

\section{Discussion}

Communities of practice in teaching are usually associated to a given group of practicing teachers working with a given set of learners identified by an academic level, by same learning objectives or by skills to acquire, in the same pedagogical context, including teaching strategies: within these communities, the same pedagogical method is generally adopted, emerged by a consensus or recommended by a hierarchy. But the way and the means used for preparing a course, what we call a Pedagogical Design Scheme, could vary from a teacher to another and, even, could depend from many variables. We assume that practicing teachers have many pedagogical design processes in mind. The instantiation of these schemes on a given course design depend all together from the learning situation, the context of design and the profile of the designer.

We have underpinned this hypothesis by the help of experimentation with the association PARTAGE. It was particularly interesting to work with the trainers employed by this association because they share in their community a very well described and tooled pedagogical approach, well-suited both for their learners characteristics and for the learning domain (concrete basic skills and procedures). This context allows us to presume on the effectiveness of teaching community of practice.

Nevertheless, the part of the experimentation related supra has proven that, confronted to the same deign task of a given learning scenario, two trainers of the teaching community have instantiated two different pedagogical design schemes, objectives driven for one and skills driven for the other.

Thus, when one wants to define methods and tools to instrument the design process of a learning scenario in a teaching community, he should support in fact more than one design process, each of them relevant from a given pedagogical design scheme.

\section{CONCLUSION}

Our engineering approach is based on patterns as a way to express teachers' pedagogical needs. Many experiments have proven the relevance of patterns in the learning scenario design activity. Our experiment allowed us to design patterns and collect pedagogical design schemes emerged from a community of trainers. Within this community, the trainers were being able to express a scenario with the editing tool we proposed and scenarios resulting were selfexpressive.

We proposed an engineering framework process and an editing tool to manage this design activity, 
able to support different pedagogical design schemes.

We experienced the capacity of patterns to represent pedagogical situation and capitalize schemes of a practice of design through pedagogical design.

Further research work will be dedicated to providing support to the designer with proposal of adaptation during the design activity. This adaptation of the pedagogical scenario design activity should take into account the design context and different pedagogical design schemes. We are developing a context-awareness and user-awareness editing tool adaptable to user's pedagogical design schemes and able to let him regulate the tool assistance.

\section{REFERENCES}

Alexander, C. Ishikawa, S. Silverstein, M., 1977 A pattern language, town, buildings, constructions, Oxford University Press

Amber, S. W. July 1998, Process pattern - building largescale systems using object technology, Cambridge University Press, ISBN 0-521-645668-9.

Bergin, J., 2000, Fourteen pedagogical patterns, in European Conference of Pattern Languages of Programs

Bonnardel N., Activités de conception et créativité : de l'analyse des facteurs cognitifs à l'assistance aux activités de conception créatives, Presses Universitaires de France ,2009

Clayer, JP. Toffolon, C. Choquet, C, A pattern-based and teacher-centered approach for learning design, Computers and Advanced Technology in Education, 2012

De Moura Filho C.O, Conceiving and Implementing a language-oriented approach for the design of automated learning scenarios, thesis, 2007

De Moura, C.O., MDEduc: conceiving and implementing a language-oriented approach for the design of automated learning scenarios, ACM SIGWEB Newsletter, 2008

Delozanne E., Le Calvez F., Merceron A. , Labat J-M, Design Patterns en EIAH : vers un langage de Patterns pour l'évaluation des apprenants. , STICEF Vol 14, 2007, p. 1-19

DPULS, 2005, DPULS Design Patterns Browser, Action du réseau d'Excellence Européen Kaleidoscope

El Kechaï H, Choquet C . Understanding the Collective Design Process by Analyzing Intermediary Objects. The 6th IEEE International Conference on Advanced Learning Technologies (ICALT'2006), isbn : 0-76952632-2, Kerkrade(The Netherlands), p.1047-1051, July $5-7,2006$

E-LEN : European project - Minerva programs: http://www2.tisip.no/E-LEN/

Emin, V., Pernin, J.-P., \& Guéraud, V. Times of Convergence. Technologies Across Learning Contexts, Lecture Notes In Computer Science, chapter
ISiS: An Intention-Oriented Model to Help Teachers, 2008, Learning Scenarios Design. vol. 5192, 338-343

Emin,V., Pernin JP., Aguirre JL., ScenEdit: an intentionoriented authoring environnment to design learning scenarios, TEL: From Innovation to Learning and Practice, Volume 6383, 2010, pp 626-631, 2010 .

Fowler, M., 1997, Analysis Patterns, Addison-Wesley, Reading MA.

Gamma, E, Helm R., Johnson R. and Vlissides J., 1995 Design Patterns: Elements of Reusable ObjectOriented Software. Addison-Wesley. ISBN 0-20163361-2.

Goodyear, P., 2005. Educational design and networked learning: Patterns, pattern language and design practice. Australasian Journal of Education Technology, 21(1), 82-101.

Hernandez-Leo D., Jorrın-Abellan I.M. , VillasclarasFernandez E.D., Asensio-Perez J.I., Dimitriadis Y., A multicase study for the evaluation of a pattern-based visual design process for collaborative learning, Journal of Visual Languages and Computing 21 (2010), p,313-331.

Hernández-Leo, D, Villasclaras-Fernández, E. D., AsensioPérez, J. I, Dimitriadis, Y., Jorrín-Abellán, I. M., RuizRequies, I., \& Rubia-Avi, B., 2006. COLLAGE: A collaborative Learning Design editor based on patterns. Educational Technology \& Society, 9 (1), 5871

IMS-LD, 2003. IMS Learning Design, http://www.imsglobal.org/ learningdesign/index.htm

Kelly S. Domain Specific Languages vs. Generic Modelling Languages, interview may 2007 : http://www.ddj.com/architect/199500627

Koper, R. ,Olivier B., Representing the Learning Design of Units of Learning, Educational Technology \& Society, 7 (3), 2004, pp 97-111

Laurillard D, Teaching as a Design Science, Building Pedagogical Patterns for Learning and Technology, Routledge edition, 2012, ISBN 978-0-415-8038.

Mor, Y. 2010 Embedding Design Patterns in a Methodology for a Design Science of e-Learning, in Christian Kohls \& Joachim Wedekind, ed., 'Problems Investigations of E-Learning Patterns: Context Factors Solutions', Information Science Publishing, Hershey, PA

Mor, Y. and Winters, N., 2007, Design approaches in technology enhanced learning , Journal of Interactive Media in Education

Paquette G., Instructional engineering for learning objects repositories networks, 2nd International Conference on Computer Aided Learning in Engineering Education, 2004, pp 25-36, Grenoble, France

Pedagogical Patterns Collector: http://thor.dcs.bbk.ac.uk/projects/LDSE/Dejan/ODC/O DC.html

Pedagogical Patterns Project: retrieved September 7, 2011 http://www.pedagogicalpatterns.org/

Rohse, S. Anderson, T, 2006, Design Patterns for Complex learning, Journal of Learning Design 2006.

Villiot-Leclercq, E. Modèle de soutien à l'élaboration et à la réutilisation de scénarios pédagogiques, thesis in computer science, 2007. 
